\title{
The association between state mandates of colorectal cancer screening coverage and colorectal cancer screening utilization among US adults aged 50 to 64 years with health insurance
}

\author{
Vilma Cokkinides ${ }^{1 *}$, Priti Bandi ${ }^{1 \dagger}$, Mona Shah $^{2 \dagger}$, Katherine Virgo $^{1 \dagger}$, Elizabeth Ward ${ }^{1 \dagger}$
}

\begin{abstract}
Background: Several states in the US have passed laws mandating coverage of colorectal cancer (CRC) screening tests by health insurance plans. The impact of these state mandates on the use of colorectal cancer screening has not been evaluated among an age-eligible target population with access to care (i.e., health care insurance coverage).

Methods: We collected information on state mandates implemented by December 31, 2008 and used data on insured adults aged 50 and 64 years from the Behavioral Risk Factor Surveillance System between 2002 and 2008 to classify individual-level exposure to state mandates for at least 1 year. Multivariate logistic regression models (with state- and year- fixed effects, and patient demographic and socioeconomic characteristics) were used to estimate the effect of state mandates on recent endoscopy screening (either flexible sigmoidoscopy or colonoscopy during the past year).
\end{abstract}

Results: From 1999-2008, twenty-two states in the US, including the District of Columbia passed comprehensive laws requiring health insurance coverage of CRC screening including endoscopy tests. Residence in states with CRC screening coverage mandates in place for at least 1 year was associated with a 1.4 percentage point increase in the probability of utilization of recent endoscopy (i.e., 17.5\% screening rates in those with mandates versus $16.1 \%$ in those without, Adjusted OR = 1.10, 95\% Cl: $1.02-1.20, p=0.02$ ).

Conclusions: The findings suggest a positive, albeit small, impact of state mandates on the use of recent CRC screening endoscopy among the target eligible population with health insurance. However, more research is needed to evaluate potential effects of mandates across health insurance types while including controls for other system-level factors (e.g. endoscopy and primary care capacity). National health insurance reform should strive towards a system that expands access to recommended CRC screening tests.

\section{Background}

Colorectal cancer (CRC) is the third leading cause of cancer-related death in the U.S. among both men and women [1]. CRC screening has been shown to reduce colorectal cancer mortality as well as incidence, by virtue of precancerous lesion detection and removal, and it has been recommended for average risk adults aged 50

\footnotetext{
* Correspondence: vcokkini@cancer.org

+ Contributed equally

'Surveillance and Health Policy Research, American Cancer Society, Atlanta, USA Full list of author information is available at the end of the article
}

and older according to clinical guidelines [1-3]. The use of CRC screening has been steadily rising; currently, about half of US adults aged 50 years and older have been screened for CRC with recommended testing modalities (i.e. either a fecal occult blood test or endoscopy tests) [4]. A number of factors are associated with lower utilization of screening including racial or ethnic minority status, lower income and educational level and either total lack of health insurance or inadequate health insurance coverage, particularly with regard to endoscopy for CRC screening [5]. Other barriers to screening 
include patients' lack of knowledge regarding screening benefits, physician's neglect to reinforce need for screening [5-8]. Based on a survey of health plans conducted in 1999-2000, it was found that most health insurance plans (97\%) covered FOBT for average risk (asymptomatic) patients. For the more invasive and expensive CRC screening procedures, such as colonoscopy, a third of the plans covered colonoscopy and nine percent covered flexible sigmoidoscopy but only for patients deemed at high-risk. Also, this survey noted that for eighty-five percent of covering plans, the patient incurred cost-sharing, through co-insurance cost and/or deductibles, for endoscopy testing procedures (average range of charges $\$ 130$ - $\$ 200$ for flexible sigmoidoscopy and \$400 - \$ 650 for colonoscopy) [9]. Patient cost-sharing has been shown to reduce utilization of preventive services and may influence preferences of CRC screening tests [10-12].

In recent years, in an effort to improve CRC screening utilization promulgated by clinical guidelines as well as to expand choice of tests given individual preferences, [13-15] state policy makers have passed legislation in several states to expand coverage for all recommended tests for CRC screening. A few states, however, have implemented policies specifying that either some CRC tests be covered (but not all) or that they be offered as part of the benefits and there remain a large number of states that currently lack regulations [16]. The purpose of this study was to assess the effect of state CRC screening coverage mandates on self-reported utilization of endoscopy (either flexible sigmoidoscopy or colonoscopy testing) among an insured population of US adults aged 50 to 64 years. Endoscopy testing was chosen as the key outcome since it is expected that state mandates requiring coverage of CRC screening would primarily impact access to these expensive CRC screening modalities.

\section{Methods}

\section{Data source}

The Behavioral Risk Factor Surveillance System (BRFSS) is a publicly available state level survey conducted in the United States that measures information on general health and cancer-related risk factors [17]. The BRFSS conducts annual, state-based telephone surveys using a multistage sampling design based on random-digitdialing methods to select a representative sample of the non-institutionalized adult civilian population, more details about the methodology can be found elsewhere [18]. This study was exempted from IRB review since it used publicly available BRFSS survey data consisting of de-identified respondents records. In this study we used four years of consecutive cross-sectional data from the 2002, 2004, 2006 and 2008 survey years of the BRFSS that collected information on two endoscopy screening modalities (flexible sigmoidoscopy or colonoscopy) [18]. Information about CRC screening mandates was derived from the Health Policy Tracking service of the American Cancer Society Cancer Action Network [16].

\section{Analytic sample}

From the compiled four-year cross-sectional BRFSS survey data, we derived an analytic sample consisting of respondents aged 50 to 64 years who indicated having any health insurance coverage and were residing in 44 states or D.C. (details of state exclusions are explained below).

\section{Variables}

\section{CRC legislation}

For the purpose of these analyses, states with coverage mandates for CRC screening were those that had implemented comprehensive legislation requiring private insurance plans to cover the full range of colorectal cancer screening tests, including endoscopy procedures, consistent with American Cancer Society guidelines [1] on or before December 31, 2008 [16]. States were excluded if they mandated partial coverage of some tests (Wyoming), "Offers" of coverage (Alabama, Oklahoma and Tennessee), or had voluntary agreements with insurance companies to provide coverage (New York and Vermont) (Table 1). For each respondent, we created a measure of CRC screening legislation 'age' (i.e., time since date of laws' implementation) by calculating the difference in years between the date of passage of the law and the date of interview. A respondent was considered as exposed if they had resided in a state with the law for 1 year or more prior to the date of their interview. Respondents who at the time of interview had mandates for less than 1 year or those in states with no mandates were considered as not exposed. As such respondents in a state in a particular year may have a different exposed/non-exposed status.

\section{CRC screening outcome}

In the BRFSS, participants were read this script ("Sigmoidoscopy and colonoscopy are exams in which a tube is inserted in the rectum to view the colon for signs of cancer or other health problems") to enable recall and reporting of endoscopy screening for CRC. Then, participants' information on endoscopy testing was collected by asking these two questions: "Have you ever had either of these exams?" and "How long has it been since you had your last sigmoidoscopy or colonoscopy?" From this information, we defined the outcome as a dichotomous (yes/no) measure of the receipt of an endoscopy CRC screening test in the past year. Though clinical guidelines recommend varying intervals for different types of endoscopy testing for CRC, we used the 'past year' interval in order to minimize potential misclassification of case/ 
Table 1 States with Colorectal Cancer Screening Coverage Mandates

\begin{tabular}{|c|c|}
\hline State & Date of implementation \\
\hline Missouri & 28-Aug-99 \\
\hline West Virginia & 1-Apr-00 \\
\hline Indiana & $1-J u l-00$ \\
\hline Virginia & 1-Jul-00 \\
\hline California & 27-Sep-00 \\
\hline Rhode Island & 31-Dec-00 \\
\hline Delaware & 1-Jan-01 \\
\hline Maryland & 1-Jul-01 \\
\hline Texas & 1-Sep-01 \\
\hline Connecticut & 1-Oct-01 \\
\hline North Carolina & 1-Jan-02 \\
\hline Distict of Columbia & 13-Apr-02 \\
\hline New Jersey & 1-Jul-02 \\
\hline Georgia & 1-Jul-02 \\
\hline Nevada & 10-Oct-03 \\
\hline Illinois & 1-Jan-04 \\
\hline Arkansas & 1-Aug-05 \\
\hline Oregon & 23-Aug-05 \\
\hline Louisiana & 1-Jan-06 \\
\hline Alaska & 1-Jan-07 \\
\hline New Mexico & 1-Apr-07 \\
\hline Washington & 1-Jul-08 \\
\hline
\end{tabular}

Note: States were excluded if they mandated partial coverage of some tests, "Offers" of coverage, or had voluntary agreements with insurance companies to provide coverage.

control status as a result of respondents' plausible migration between states with and without laws.

\section{Covariates}

All multivariate analyses controlled for age (categorized as 50 to 54 years old, 55 to 59 years old and 60 to 64 years old), sex (male vs female), race/ethnicity (nonHispanic White, non-Hispanic Black, Hispanic, and others races), education level (having less than or equal to a high school degree versus having some college or college graduate education), household income level (annual income of less than $\$ 25,000$, between $\$ 25,000$ to less than $\$ 50,000$, over $\$ 50,000$ and a category of 'missing' was included also since more than five percent of the sample had 'unknown' income information), selfreported health status (categories of fair or poor health, good and better health), and marital status (married, single and divorced/widowed or separated individuals). Even though state mandates primarily affect privately insured populations, the BRFSS did not collect information about the type of health plans among those with health insurance coverage. As we could not restrict our analytic sample to the privately insured group, we considered a state level variable measuring the privately insured proportion among 50-64-year-olds (divided into tertiles and classified as high, medium, and low) for
2002, 2004, 2006 and 2008 as a covariate in all statistical models [19] in addition to controlling for respondents' socioeconomic status.

\section{Statistical analysis}

The independent effect of state CRC screening coverage mandates on CRC screening was evaluated using stateand year- fixed effects models. Multivariate logistic regression analyses were used to calculate adjusted probabilities (predicted marginals) and odds ratios of colorectal cancer screening among respondents with and without state coverage mandates. Models included a state fixed effect that controlled for state factors that do no vary over time (invariant factors) and a year effect that controlled for national secular trends, in addition to individual-level covariates, and state privately insured population rates among those 50-64 years. We present these estimates in comparison with unadjusted probabilities (obtained from unadjusted logistic regression models) in order to understand the influence of other covariates on the relationship between state mandates' exposure and screening probabilities. Further, we performed sensitivity analysis that considered a lag variable in order to capture the effect of mandates at different times after implementation. We tested for significant differences in the adjusted rates among residents in states with mandates for different time periods after implementation ( 1 year, 2 to 4 years, 5 years or more).

We tested for potential two- and three-way interactions between the mandates and demographic (race and ethnicity) and SES variables (education- and incomelevel), as it is plausible that the effect of these mandates would be more concentrated among certain groups than others, given that some groups may have had lower access to these tests prior to the passage of these mandates and may thus benefit more after these laws are passed. SAS-callable-SUDAAN Version 10 was used to apply the sampling weights in the calculation of weighted estimates and standard errors (using Taylor Series Linearization Method [20]) that take into account the complex survey design of the BRFSS surveys [18].

\section{Results}

\section{State mandates and Sample characteristics}

Of the 45 states included in the study, 22 states and DC had passed mandates requiring private insurance plans to cover the full range of colorectal cancer screening tests consistent with ACS guidelines on or before December 31, 2008 (Table 1). The analytic sample consisted of 293,626 individuals aged 50-64 years who reported having health insurance coverage (Table 2). Respondents were evenly distributed across years (2002 to 2008 ) and between the sexes (49\% male vs. $51 \%$ female). Individuals were mostly in the age-groups of 
Table 2 Descriptive characteristics of US Adults with Health Insurance, aged 50-64 years, surveyed in the period of 2002-2008

\begin{tabular}{|c|c|c|c|}
\hline \multirow{2}{*}{$\begin{array}{l}\text { Characteristics } \\
\text { Year of the survey }\end{array}$} & \multicolumn{2}{|c|}{$\begin{array}{c}\text { Unweighted, } \\
\text { N (\%) }\end{array}$} & \multirow[t]{2}{*}{ Weighted \% } \\
\hline & & & \\
\hline 2002 & 45465 & $(15.5)$ & 22.3 \\
\hline 2004 & 62271 & $(21.2)$ & 23.7 \\
\hline 2006 & 82923 & $(28.2)$ & 26.1 \\
\hline 2008 & 102967 & $(35.1)$ & 27.9 \\
\hline \multicolumn{4}{|l|}{ Age } \\
\hline $50-54$ & 105041 & $(35.8)$ & 40.6 \\
\hline $55-59$ & 100781 & $(34.3)$ & 32.8 \\
\hline $60-64$ & 87804 & $(29.9)$ & 26.6 \\
\hline \multicolumn{4}{|l|}{ Sex } \\
\hline Male & 117328 & $(40.0)$ & 49.0 \\
\hline Female & 176298 & $(60.0)$ & 51.0 \\
\hline \multicolumn{4}{|l|}{ Annual Household income } \\
\hline$<25,000$ & 50398 & $(17.2)$ & 14.8 \\
\hline $25,000-<50,000$ & 75277 & $(25.6)$ & 23.6 \\
\hline$>=50000$ & 135243 & $(46.1)$ & 50.8 \\
\hline Missing & 32568 & $(11.1)$ & 10.8 \\
\hline \multicolumn{4}{|l|}{ Education } \\
\hline Less than high school or High School & 100382 & $(34.2)$ & 34.2 \\
\hline Some college or College graduate & 192786 & $(65.8)$ & 65.8 \\
\hline \multicolumn{4}{|l|}{ Race } \\
\hline White, non-Hispanic & 246930 & $(84.4)$ & 79.1 \\
\hline Black, non-Hispanic & 19904 & $(6.8)$ & 8.0 \\
\hline Hispanic & 10685 & $(3.7)$ & 7.4 \\
\hline Other, Multi-racial, non-Hispanic & 13615 & $(4.7)$ & 5.5 \\
\hline \multicolumn{4}{|l|}{ Health status } \\
\hline Excellent or Very good & 678834 & $(51.5)$ & 53.6 \\
\hline Good & 396194 & $(30.1)$ & 30.1 \\
\hline Fair or poor & 241939 & $(18.4)$ & 16.3 \\
\hline \multicolumn{4}{|l|}{ Marital status } \\
\hline Divorced/Widowed/Separated & 81354 & $(27.8)$ & 20.0 \\
\hline Single & 21170 & $(7.2)$ & 5.2 \\
\hline Married/member of unmarried couple & 190143 & $(65.0)$ & 74.7 \\
\hline \multicolumn{4}{|l|}{ State privately insured population* } \\
\hline Low & 79047 & $(26.9)$ & 38.7 \\
\hline Medium & 101351 & $(34.5)$ & 30.2 \\
\hline High & 113228 & $(38.6)$ & 31.1 \\
\hline
\end{tabular}

Note: Missing responses constituted less than $0.8 \%$ on all of the above variables, except income for which missing values were coded as a separate category. * State-level variable from the Census[19] and expressed in tertiles of the distribution of the states' proportion of adults aged 50 to 64 years with private insurance.

50-54 (40.6\%) and 55-59 years (32.8\%), were primarily White, non-Hispanic (79.1\%), had college or some college degrees (65.8\%), and in higher- and middle-household income groups ( $\geq \$ 50,000: 50.8 \%, 25,000$ to 550,000: $23.6 \%$ ). The majority of respondents reported "better" or "good" health status (81.9\%), and were married or members of unmarried couples (74.7\%)
(Table 2). Across states, the percent of the population 50-64 years who were privately insured averaged over 2002-2008 was generally high and ranged from 69\% in Arkansas to $88 \%$ in Minnesota (data not shown).

\section{Impact of state CRC screening mandates on CRC screening utilization in the past year}

In unadjusted analyses, having a state CRC screening mandate for at least 1 year was associated with a $0.4 \%$ point increase in the probability of flexible sigmoidoscopy or colonoscopy in the past year (OR: 1.03, 95\% CI: $0.99,1.08, \mathrm{p}=0.09$ ) (Table 3). Adjustment for stateand year-fixed effects, individual covariates, and statelevel proportions of privately insured adults resulted in a stronger mandate effect compared to unadjusted analyses; the probability of CRC screening was $1.4 \%$ points higher among individuals residing in states with mandates than those without (17.5\% vs. $16.1 \%$, OR: 1.10 , 95\% CI: 1.02, 1.20, p = 0.02) (Table 3). Additionally, we considered the possibility that state mandates require more than one year of implementation to be effective in changing CRC utilization patterns. CRC utilization rates did not differ significantly between respondents in states with laws in place for different time intervals.

The two-way interaction terms between state mandates and demographic- and socioeconomic- variables were not statistically significant; indicating that the effect of mandates did not differ significantly between subgroups of respondents based on their race/ethnicity, education, and household income levels (data not shown). However, linear contrasts of the adjusted probabilities indicated that the effect of mandates was significant and stronger in higher-educated respondents $(16.7 \%$ vs. $18.3 \%$, contrast: $1.6 \%$ points, $\mathrm{p}=0.01$ ) but not in lower-educated respondents $(15 \%$ vs. $15.8 \%$, contrast: $0.8 \%, \mathrm{p}=0.12)$. A three-way interaction variable between state mandates, a collapsed two-level version of the household income (low- and middle-income: $<\$ 50,000$, and high income group: $\geq \$ 50,000$ ), and education level (lower-education: less than high school or high school graduate, and higher-education: college graduate or some college graduate) was statistically significant ( $<0.005)$. Linear contrasts of the adjusted probabilities from the interaction term indicated that among low- and middle-income individuals, the effect of state mandates was positive and significant only among higher-educated individuals $(14.4 \%$ vs. $17.9 \%$, contrast: $3.5 \%$ points, $\mathrm{p}<0.001)$ but not among lower-educated individuals (13.7\% vs. $14.1 \%$, contrast: $0.4 \%$ points, $\mathrm{p}=0.5)$. Conversely, state mandates resulted in marginally higher CRC utilization rates among lower educated-high income individuals (15.3\% vs. $18.0 \%$, contrast: $2.7 \%$ points, $\mathrm{p}<0.05)$, but not among high educated-high income individuals (17.9\% vs. $19.1 \%$, contrast: $1.2 \%$ points, $\mathrm{p}=0.12$ ). 
Table 3 Impact of Colorectal Cancer Screening coverage mandates on Endoscopy Screening ${ }^{a}$ Use in Past Year among US Adults with Health Insurance aged 50-64 years, 2002-2008

\begin{tabular}{|c|c|c|c|c|}
\hline Characteristic & $\begin{array}{c}\text { Unadjusted prevalence } \\
(95 \% \mathrm{Cl})\end{array}$ & OR $(95 \% \mathrm{Cl})$ & $\begin{array}{c}\text { Adjusted prevalence }{ }^{\mathrm{b}} \\
(95 \% \mathrm{Cl})\end{array}$ & OR $(95 \% \mathrm{Cl})$ \\
\hline \multicolumn{5}{|l|}{ CRC Screening Mandate } \\
\hline State mandate for at least 1 year & $16.9( \pm 0.4)$ & $1.03(0.99,1.08)$ & $17.5( \pm 0.7)$ & $1.10(1.02,1.20)^{*}$ \\
\hline $\begin{array}{r}\text { State mandate for less than } 1 \text { year or No state } \\
\text { mandate }\end{array}$ & $16.5( \pm 0.4)$ & 1.00 & $16.1( \pm 0.5)$ & 1.00 \\
\hline \multicolumn{5}{|l|}{ Covariates } \\
\hline \multicolumn{5}{|l|}{ Year of the survey } \\
\hline 2008 & $17.9( \pm 0.4)$ & $1.23(1.16,1.3)^{* * *}$ & $17.5( \pm 0.5)$ & $1.16(1.09,1.24)^{* * *}$ \\
\hline 2006 & $17.4( \pm 0.6)$ & $1.18(1.12,1.25)$ & $17.2( \pm 0.5)$ & $1.13(1.06,1.21)$ \\
\hline 2004 & $16.0( \pm 0.6)$ & $1.07(1.01,1.14)$ & $16.1( \pm 0.6)$ & $1.05(0.98,1.12)$ \\
\hline 2002 & $15.1( \pm 0.6)$ & 1.00 & $15.5( \pm 0.6)$ & 1.00 \\
\hline \multicolumn{5}{|l|}{ Age } \\
\hline $50-54$ & $15.2( \pm 0.4)$ & $0.77(0.73,0.81)^{* * *}$ & $15.1( \pm 0.4)$ & $0.76(0.72,0.79)^{* * * *}$ \\
\hline $55-59$ & $16.8( \pm 0.4)$ & $0.87(0.83,0.91)$ & $16.7( \pm 0.5)$ & $0.86(0.81,0.90)$ \\
\hline $60-64$ & $18.9( \pm 0.6)$ & 1.00 & $19.0( \pm 0.5)$ & 1.00 \\
\hline \multicolumn{5}{|l|}{ Sex } \\
\hline Male & $16.9( \pm 0.4)$ & $1.04(1.00,1.08)^{*}$ & $16.8( \pm 0.4)$ & $1.01(0.97,1.05)$ \\
\hline Female & $16.4( \pm 0.4)$ & 1.00 & $16.6( \pm 0.3)$ & 1.00 \\
\hline \multicolumn{5}{|l|}{ Annual Household Income } \\
\hline$<25,000$ & $15.5( \pm 0.6)$ & $0.86(0.81,0.91)^{* * *}$ & $14.7( \pm 0.7)$ & $0.80(0.75,0.86)^{* * *}$ \\
\hline $25,000-<50,000$ & $15.4( \pm 0.6)$ & $0.85(0.81,0.89)$ & $15.5( \pm 0.5)$ & $0.85(0.81,0.89)$ \\
\hline$>=50000$ & $17.5( \pm 0.4)$ & 1.00 & $17.7( \pm 0.4)$ & 1.00 \\
\hline Missing & $17.2( \pm 0.8)$ & $0.98(0.92,1.04)$ & $17.1( \pm 0.8)$ & $0.96(0.89,1.02)$ \\
\hline \multicolumn{5}{|l|}{ Education } \\
\hline Less than high school or High School & $15.4( \pm 0.4)$ & $0.87(0.83,0.90)^{* * *}$ & $15.3( \pm 0.5)$ & $0.86(0.82,0.90)^{* * *}$ \\
\hline Some college or College graduate & $17.4( \pm 0.4)$ & 1.00 & $17.4( \pm 0.4)$ & 1.00 \\
\hline \multicolumn{5}{|l|}{ Race } \\
\hline Black, non-Hispanic & $20.7( \pm 1.2)$ & $1.33(1.24,1.43)^{* * *}$ & $21.1( \pm 1.2)$ & $1.38(1.28,1.48)^{* * *}$ \\
\hline Hispanic & $15.3( \pm 1.4)$ & $0.92(0.82,1.03)$ & $16.3( \pm 1.5)$ & $1.01(0.90,1.13)$ \\
\hline Other, Multi-racial, non-Hispanic & $16.5( \pm 1.6)$ & $1.00(0.89,1.14)$ & $16.9( \pm 1.7)$ & $1.05(0.93,1.19)$ \\
\hline White, non-Hispanic & $16.4( \pm 0.2)$ & 1.00 & $16.3( \pm 0.3)$ & 1.00 \\
\hline \multicolumn{5}{|l|}{ Health status } \\
\hline Fair or poor health & $19.2( \pm 0.8)$ & $1.24(1.18,1.3)^{* * *}$ & $20.4( \pm 0.8)$ & $1.36(1.29,1.44)^{* * *}$ \\
\hline Good or better health & $16.1( \pm 0.2)$ & 1.00 & $15.9( \pm 0.3)$ & 1.00 \\
\hline \multicolumn{5}{|l|}{ Marital status } \\
\hline Divorced/Widowed/Separated & $15.9( \pm 0.6)$ & $0.92(0.88,0.96)^{* * *}$ & $15.9( \pm 0.5)$ & $0.92(0.88,0.97)^{* * *}$ \\
\hline Single & $15.2( \pm 1.2)$ & $0.87(0.8,0.95)$ & $15.2( \pm 1.1)$ & $0.87(0.80,0.96)$ \\
\hline Married/member of unmarried couple & $17.0( \pm 0.4)$ & 1.00 & $17.0( \pm 0.3)$ & 1.00 \\
\hline \multicolumn{5}{|l|}{ State privately insured population } \\
\hline Low & $16.4( \pm 0.5)$ & $0.92(0.88,0.96)^{* * *}$ & $16.9( \pm 1.1)$ & $1.02(0.89,1.17)$ \\
\hline Medium & $16.2( \pm 0.4)$ & $0.91(0.87,0.94)$ & $16.6( \pm 0.7)$ & $1.00(0.93,1.07)$ \\
\hline High & $17.6( \pm 0.4)$ & 1.00 & $16.6( \pm 0.9)$ & 1.00 \\
\hline
\end{tabular}

${ }^{*} \mathrm{p}<0.05,{ }^{* *} \mathrm{P}<0.01,{ }^{* * *} \mathrm{p}<0.001 ; 95 \% \mathrm{Cl}: 95 \%$ confidence interval; OR: Odds ratio; CRC: Colorectal Cancer.

${ }^{a}$ Endoscopy screening is defined as having ever had either sigmoidoscopy and colonoscopy and reporting receipt of any of these screening tests in the past year. ${ }^{\mathrm{b}}$ Adjusted prevalences are predicted marginals derived from multivariate logistic models predicting endoscopy use, that adjusted for covariates listed above, in addition to state fixed effects.

\section{Discussion}

In this study, we provide the first assessment of the utilization effects of state mandates requiring private insurers to cover recommended CRC screening. The main findings suggest that state mandates are positively associated with utilization of CRC endoscopic screening (1.4\% absolute increase in probability of past-year endoscopy test use) in adults aged 50 to 64 years with access to care. In addition, our results suggest that among lowand middle- income groups, mandates seemed to have 
benefited higher-educated groups more than lowereducated, whereas education-related disparities in high income groups appear to have been reduced as a result of mandates. Even though we know of no prior study that has examined this association in a non-Medicare insured population of adults aged 50 to 64 years, our study findings are generally consistent with previous studies conducted among the elderly Medicare beneficiaries, showing positive effects of policy changes [21-24].

In reflecting on these study's finding suggesting a small effect of state CRC screening mandates (in absolute percentage differences), we have to consider several contextual issues and challenges that may stimulate additional health policy research endeavors. First, there is the issue that state-mandated benefits for CRC screening are limited in their reach because of certain exemptions. State mandates only apply to certain types of insurance coverage in the commercial private marketplace. It is the case that, the federal Employee Retirement Income Security Act (ERISA) exempts states from regulating self-funded employer-based health plans from state laws that govern health insurance $[25,26]$. We were unable to distinguish and exclude individuals subject to these self-insured plans, potentially biasing our estimates towards the null. Secondly, we had very limited information on respondents' health insurance plans. We were unable to restrict our sample to privately insured respondents, although we considered the inclusion of a state measure of privately insured populations as an adjustment factor. Further, we could not account for potential differences across types of private insurance (e. g. managed-care plans, fee-for-service, high-deductible health service accounts, etc); such variations in types of private insurance arrangements may play a role in utilization of medical services [27]. Thirdly, although mandated benefits for CRC screening may have expanded options for CRC testing modalities they do not address the cost-sharing requirements for the more expensive modalities (i.e., sigmoidoscopy and colonoscopy). Studies have shown that patient-cost sharing requirements influence preferences for specific CRC screening tests and are likely to reduce utilization of preventive services [10-12]. Another issue is that despite state-mandated benefits resulting in changes to health plan policies for CRC screening, certain socioeconomic segments may still access these expanded benefits at disproportionately lower/higher rates vis-à-vis other groups. Our results suggest CRC endoscopy uptake patterns after passage of state mandates may be a function both individuals' education and income levels which may in turn relate to other influences such as patients' knowledge of expanded benefits and eligibility requirements and receipt of healthcare provider CRC screening recommendation [28-30]. Despite state mandates, patients' ability to obtain an endoscopy test (or a referral) may be affected by the availability of endoscopy-infrastructure services/providers. Thus, future studies are needed to better characterize whether and how these issues/concerns affect the robustness/validity of our findings. Lastly, our study was limited by its reliance on selfreported survey data and so future studies based on claims and/or clinic records are needed.

\section{Conclusion}

Screening for colorectal cancer is a beneficial, costeffective way to advance the public's health by reducing the incidence and mortality of CRC $[1,5]$. Colorectal cancer screening has been designated as one of the highest priority preventive services by the National Commission on Preventive Priorities based on the burden of disease that could be prevented [31,32]. It is increasingly recognized that all age-eligible asymptomatic adults have adequate and affordable access to all recommended screening procedures in order to improve survival and quality of life [27]. Our study suggests that state mandates for CRC screening test coverage may increase utilization among insured individuals. Through advocacy efforts, colorectal cancer screening and prevention has been part of the national healthcare reform discussions and much is expected with the recent passage of landmark federal legislation, the Patient Protection and Affordable Care Act [33]. This Act requires all new private health plans cover colorectal cancer screening tests with a U.S. Preventive Services Task Force (USPSTF) rating of "A" or "B" without any out-of-pocket costs to patients [34]. Now, with the advent of its implementation, there is yet the potential for future improvements in CRC screening test utilization as it intends to prioritize access to preventive care for all, including previously uninsured individuals.

\section{Acknowledgements}

We thank Dana Flanders, PhD. for his valuable statistical consultation on the methods and statistical analysis of the study.

\section{Author details \\ 'Surveillance and Health Policy Research, American Cancer Society, Atlanta, USA. ${ }^{2}$ Cancer Action Network - American Cancer Society, Washington DC, USA.}

\section{Authors' contributions}

VC initiated the research idea, designed the study, and wrote the manuscript. PB contributed to the study design, conducted the analysis and wrote parts of the manuscript. MS provided valuable support in the compilation of state mandates information as well as review/editing of the manuscript. KV provided valuable comments on the analysis and editorial suggestions on the manuscript. EW provided valuable comments and editorial suggestion on the manuscript. All authors read and approved the final manuscript.

\section{Competing interests}

The authors declare that they have no competing interests. 
Received: 6 August 2010 Accepted: 27 January 2011

Published: 27 January 2011

\section{References}

1. Levin B, Lieberman DA, McFarland B, Smith RA, Brooks D, Andrews KS, Dash C, Giardiello FM, Glick S, Levin TR, et al: Screening and Surveillance for the Early Detection of Colorectal Cancer and Adenomatous Polyps, 2008: A Joint Guideline from the American Cancer Society, the US MultiSociety Task Force on Colorectal Cancer, and the American College of Radiology. CA Cancer J Clin 2008, 58(3):130-160.

2. US Preventive Services Task Force: Screening for colorectal cancer: recommendations and rationale. Agency for Healthcare Research and Quality, Rockville, MD; 2002.

3. Allen JD, Barlow WE, Duncan RP, Egede LE, Friedman LS, Keating NL, Kim P, Lave JR, Laveist TA, Ness RB, et al: NIH State-of-the-Science Conference Statement: Enhancing Use and Quality of Colorectal Cancer Screening. NIH 2010, 27(1)

4. Smith RA, Cokkinides V, Brooks D, Saslow D, Brawley OW: Cancer screening in the United States, 2010: a review of current American Cancer Society guidelines and issues in cancer screening. CA Cancer J Clin 2010, 60(2):99-119.

5. Holden DJ, Jonas DE, Porterfield DS, Reuland D, Harris R: Systematic review: enhancing the use and quality of colorectal cancer screening Ann Intern Med 2010, 152(10):668-676.

6. Zapka JG, Puleo E, Vickers-Lahti M, Luckmann R: Health systems factors and colorectal cancer screening. Am J Prev Med 2002, 23(1):28-35.

7. Adams EK, Thorpe KE, Becker ER, Joski PJ, JF: Colorectal cancer screening, 1997-1999: role of income, insurance and policy. Prev Med 2005 38(5):551-557.

8. Farmer MM, Bastani R, Kwan L, Belman M, Ganz PA: Predictors of colorectal cancer screening from patients enrolled in a managed care health plan. Cancer 2008, 112(6):1230-1238.

9. Klabunde CN, Riley GF, Mandelson MT, Frame PS, Brown ML: Health plan policies and programs for colorectal cancer screening: a national profile. Am J Manag Care 2004, 10(4):273-279.

10. Pignone M, Bucholtz D, Harris R: Patient preferences for colon cancer screening. J Gen Intern Med 1999, 14:432-437.

11. Varghese RK, Friedman C, Ahmed F, Franks AL, Manning M, Seeff LC: Does Health Insurance Coverage of Office Visits Influence Colorectal Cancer Testing. Cancer Epidemiol Biomarkers Prev 2005, 14(3):744-747.

12. Wharam JF, Galbraith AA, Kleinman KP, Soumerai SB, Ross-Degnan D, Landon BE: Cancer Screening before and after Switching to a HighDeductible Health Plan. Ann Intern Med 2008, 148:647-655.

13. Powell AA, Burgess DJ, Vernon SW, Griffin JM, Grill JP, Noorbaloochi S, Partin MR: Colorectal cancer screening mode preferences among US veterans. Prev Med 2009, 49(5):442-448.

14. Jones RM, Woolf SH, Cunningham TD, Johnson RE, Krist AH, Rothemich SF, Vernon SW: The Relative Importance of Patient-Reported Barriers to Colorectal Cancer Screening. 38 2010, 5:499-507.

15. Fletcher RH, Colditz GA, Pawlson LG, Richman H, Rosenthal D, Salber PR: Screening for colorectal cancer: the business case. Am J Manag Care 2002, 8:531-538.

16. Issue Brief: How do you measure up? A Progress Report on State Legislative Activity to reduce cancer incidence and mortality. 2010 [http://acscan.org/static/measure/].

17. Centers for Disease Control and Prevention (CDC): Behavioral Risk Factor Surveillance System operational and user's guide. Atlanta, GA: US Department of Health and Human Services, CDC; 2006 [http://www.cdc. gov/BRFSS/, Accessed Jun 15, 2010

18. Centers for Disease Control and Prevention (CDC): Behavioral Risk Factor Surveillance Systems - Technical Documentation. 2010 [http://www.cdc. gov/brfss/technical_infodata/surveydata.htm]

19. Census: American Community Survey 2002-2008. U.S Census Bureau: DataFerrett; 2010.

20. SUDAAN: version 9.0.0 Software for the Statistical Analysis of Correlated Data. Research Triangle Institute, Inc NC; 2002

21. Meissner HI, Breen N, Klabunde CN, Vernon SW: Patterns of colorectal cancer screening uptake among men and women in the United States. Cancer Epidemiol Biomarkers Prev 2006, 15(2):389-394.
22. Schenck AP, Peacock SC, Klabunde CN, Lapin P, Coan JF, Brown ML: Trends in colorectal cancer test use in the Medicare population, 1998-2005. Am J Prev Med 2009, 37:1-7.

23. Harewood GC, Lieberman DA: Colonoscopy practice patterns since introduction of Medicare coverage for average-risk screening. Clin Gastroenterol Hepatol 2004, 2(1):72-77.

24. Prajapati DN, Saeian K, Binion DG, Staff DM, Kim JP, Massey BT, Hogan WJ: Volume and yield of screening colonoscopy at a tertiary medical center after change in medicare reimbursement. Am J Gastroenterol 2003, 98(1):194-199.

25. Issue Brief. State strategies for curbing colorectal cancer screening. NGA Center for Best Practices, Washington DC; 2008.

26. Buchmueller TC, Cooper PF, Jacobson M, Zuvekas SH: Parity for Whom? Exemption and the extent of state mental health parity legislation. Health Affairs 2007, 26(4):w483-487

27. Barrera E, Ward E, Shah M: Impact of Health insurance on colorectal cancer screening. In Early Detection and Prevention of Colorectal Cancer. Edited by: Kim KE. SLACK Incorporated, Thorofare, NJ; 2009.

28. Ruffin MT, Creswell JW, Jimbo M, Fetters MD: Factors influencing choices for colorectal cancer screening among previously unscreened African and Caucasian Americans: findings from a triangulation mixed methods investigation. J Community Health 2009, 34(2):79-89.

29. Hawley ST, Volk RJ, Krishnamurthy P, Jibaja-Weiss M, Vernon SW, S K: Preferences for colorectal cancer screening among racially/ethnically diverse primary care patients. Med Care 2008, 46(9 Suppl 1):S10-16.

30. Ye J, Xu Z, Aladesanmi O: Provider recommendation for colorectal cancer screening: examining the role of patients' socioeconomic status and health insurance. Cancer Epidemiol Biomarkers Prev 2009, 33:207-211.

31. Maciosek MV, Edwards NM, Coffield AB, Flottemesch TJ, Nelson WW Goodman MJ, Solberg LI: Priorities among effective clinical preventive services: methods. Am J Prev Med 2006, 31(1):90-96.

32. Maciosek MV, Solberg LI, Coffield AB, Edwards NM, Goodman MJ: Colorectal cancer screening: health impact and cost effectiveness. Am J Prev Med 2006, 31(1):80-89.

33. The Patient Protection and Affordable Care Act. Pub L. No. 111-148. 2011 [http://www.healthcare.gov/law/about/index.html ].

34. Interim Final Rules for Group Health Plans and Health Insurance Issuers relating to coverage of preventive services under the Patient Protection and Affordable Care Act, July 19 2010. 2011 [http://www.healthcare.gov/ law/provisions/preventive/moreinfo.html].

Pre-publication history

The pre-publication history for this paper can be accessed here: http://www.biomedcentral.com/1472-6963/11/19/prepub

doi:10.1186/1472-6963-11-19

Cite this article as: Cokkinides et al:: The association between state mandates of colorectal cancer screening coverage and colorectal cancer screening utilization among US adults aged 50 to 64 years with health insurance. BMC Health Services Research 2011 11:19.

\section{Submit your next manuscript to BioMed Central and take full advantage of:}

- Convenient online submission

- Thorough peer review

- No space constraints or color figure charges

- Immediate publication on acceptance

- Inclusion in PubMed, CAS, Scopus and Google Scholar

- Research which is freely available for redistribution

Submit your manuscript at www biomedcentral com/submit
C Biomed Central 